\title{
An efficient transient gene expression system using aleurones of diploid wheat seeds
}

\author{
Shigeko Utsugi*, Masahiko Maekawa, Kazuhiko Noda \\ Research Institute for Bioresources, Okayama University, 2-20-1 Chuo, Kurashiki, Okayama 710-0046, Japan \\ *E-mail: utsugi@rib.okayama-u.ac.jp Tel \& Fax: +81-86-434-1215
}

Received December 6, 2005; accepted April 21, 2006 (Edited by S. Ogita)

\begin{abstract}
To establish a transient gene expression system for investigating the molecular function of genes in mature wheat seeds, we bombarded embryos or aleurones of three hexaploid wheat (Triticum aestivum L.) varieties Chinese Spring, RL4137 and OS21-5, two diploid wheat (T. monococcum L.) varieties KT3-1 and KT3-5 and a barley (Hordeum vulgare, L.) variety Himalaya with fusion constructs containing the GUS reporter gene driven by the Actin1 promoter or $\alpha$-amylase promoter using a particle gun, and compared the efficiency of gene expression for the transient assay. The efficiency of transient expression was high in aleurone tissues of OS21-5, KT3-1, KT3-5 and Himalaya. In the aleurone tissues of KT3-5, the $\alpha$-amylase promoter was especially markedly activated by gibberellic acid (GA) and by a GA-inducible MYB transcription activator of T. monococcum, TmGAMYB. This assay system using the aleurone tissues of KT3-5 may be especially useful for investigating which genes are expressed and how they are regulated in germinating wheat seeds.
\end{abstract}

Key words: Aleurone, $\alpha$-amylase, GA, transient assay, wheat.

Transient gene expression systems are important tools for understanding the functions of genes in specific organs of plants, and are especially useful for analyzing various gene functions in the aleurones of cereal seeds. In wheat, however, there have been no efficient transient gene expression systems using mature seeds so far.

Aleurones of cereal seeds are known to have various functions in relation to their response to plant hormones such as GA and ABA, signal transduction and transport of various substances (Gilroy and Jones 1994; Lovegrove and Hooley 2000). Thus, aleurone tissues are suitable materials for investigating regulation mechanisms of certain genes that respond to GA and ABA, which control seed germination and dormancy. Aleurone cells have important roles in signal transduction triggered by GA that is synthesized in embryos and secreted from embryos to aleurones. Transient assay systems using aleurones of cereals were crucial for investigating regulations of some specific genes, Em, dehydrin and $\alpha$ amylase etc., which are involved in seed dormancy and germination in cereals (Jacobsen and Close 1991; Robertson et al. 1995; Vasil et al. 1995). In barley, a direct transient assay system for aleurone tissues has been used by several groups (Shen et al. 2001; GomezCadenasm et al. 2001; Zentella et al. 2002).
One of the keys to improving grain quality is the control of seed germination and dormancy especially in wheat. We conducted this study to construct an efficient transient assay system using mature wheat seeds for molecular biological studies mainly on seed germination. We used three hexaploid wheat varieties Chinese Spring, RL4137 and OS21-5, and two diploid wheat varieties KT3-1 and KT3-5. Chinese spring is a standard line for genetic studies in common wheat. RL4137 and OS21-5 are independent lines that have been used for some physiological experiments in our laboratory. KT3-1 and KT3-5 are varieties of the diploid wheat, $T$. monococcum, the latter being an early flowering mutant line induced by EMS-treatment of the former line. As a control, we also used a barley variety Himalaya, often used for studies on seed germination, due to its high sensitivity to GA (Shen et al. 2001; Gomez-Cadenasm et al. 2001; Zentella et al. 2002).

In the first experiment, we performed a transient expression analysis using mature seeds of a hexaploid wheat variety Chinese Spring, a diploid wheat variety KT3-5 and a barley variety Himalaya. Mature seeds sterilized in $2 \%$ sodium hypochlorite solution were either longitudinally cut into half-grains or processed to isolate the embryos. The half-grains or isolated embryos were

Abbreviations: ABA, abscisic acid: CaMV, cauliflower mosaic virus: cDNA, complementary DNA: DAP, day after pollination: GA, gibberellic acid: GFP, green fluorescent protein: GUS, $\beta$-glucuronidase: LUC, luciferase: MS medium, Murashige-Skoog medium: NOS, nopaline synthase.

This article can be found at http://www.jspcmb.jp 
incubated on Murashige-Skoog medium (MS, Sigma) agar plates without sucrose at $4^{\circ} \mathrm{C}$ for 3 days for imbibition. For bombardment by a particle gun (Bio-Rad biolistic PDS-1000/ He particle delivery system), two $\mu \mathrm{g}$ of a rice Actin1 promoter- $\beta$-glucuronidase (GUS) reporter fusion construct ( $p A c t 1-\mathrm{F}$ ) (McElroy et al. 1990) purified by Quiagan tip (Quiagan) was precipitated onto $0.75 \mathrm{mg}$ of $1.6 \mu \mathrm{m}$ gold particles. The gold particles coated with the DNA were spread onto rupture discs. The half-grains or isolated embryos were then bombarded with the DNA-coated gold particles from a distance of $5 \mathrm{~cm}$ under a pressure of $1100 \mathrm{psi}$. The distance and pressure used here have been previously determined as optimum in some experiments using some materials including protoplasts and cultured cells derived from wheat aleurone tissues (data not shown). The tissues were subsequently incubated at $24^{\circ} \mathrm{C}$ for 2 days and used for the histochemical GUS assay. GUS staining was performed by incubating the tissues in phosphate buffer containing $0.06 \%$ Triton X-100, $1 \mathrm{mM}$ 5-bromo-4chloro-3-indolyl $\beta$-D-glucuronic acid (X-gluc), $0.5 \mathrm{mM}$ $\mathrm{K}_{3}\left[\mathrm{Fe}(\mathrm{CN})_{6}\right], 0.5 \mathrm{mM} \mathrm{K}_{4}\left[\mathrm{Fe}(\mathrm{CN})_{6}\right], 10 \mathrm{mM}$ EDTA and $10 \mathrm{gl}^{-1}$ cycloheximide for $24 \mathrm{~h}$ at $37^{\circ} \mathrm{C}$. The stained tissues were treated with ethanol several times for bleaching.

Patterns of GUS expression differed with the material as described below. Only a few GUS spots were observed in the embryos and seeds of Chinese Spring (Figure 1A and D), while high levels of GUS activity were detected in tissues other than the endosperms, i.e., in the embryos and aleurone layers, of KT3-5 (Figure 1B and E). GUS expression was also observed in the embryos of Himalaya (Figure 1C).

To examine whether the wheat aleurone tissues are suitable for the assay system, the tissues of certain wheat varieties were bombarded with a reporter construct containing a GUS gene driven by the high-pI $\alpha$-amylase promoter, Am (-877) IGN (Jacobsen and Close 1991), and the transient expressions of the reporter construct were compared. This expression system is important for studying the functions of $\alpha$-amylase, a gene encoding a key enzyme involved in GA-regulated seed germination. GA is not synthesized endogenously in aleurones, but synthesized in embryos and secreted into them during seed germination. Aleurone tissues, from which embryos have been removed, are thus ideal materials for examining the effect of exogenous GA.

For the transient assay described below, half-grains without embryos were incubated on MS plates without sucrose at $4^{\circ} \mathrm{C}$ for 3 days. Then, the half-grains were cut longitudinally, and the aleurone tissues were isolated by removing the starchy endosperms. Twenty pieces of aleurone tissues (approximately $25 \mathrm{~mm}^{2}$ ) were placed on each plate and bombarded with DNA-coated particles. The expression of $\alpha$-amylase was analyzed by
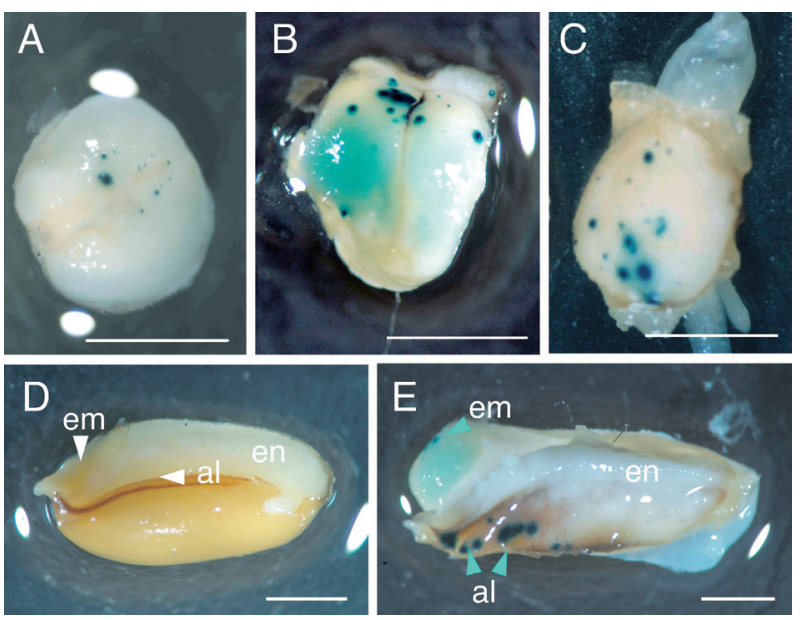

Figure 1. Histochemical staining of wheat and barley seeds and embryos bombarded with the pActl-F construct. Longitudinally cut seeds or isolated embryos were bombarded, incubated at $24{ }^{\circ} \mathrm{C}$ for $48 \mathrm{~h}$ and subjected to GUS staining. GUS expressions in embryos of Chinese Spring (A), KT3-5 (B) and barley (C) carrying the pAct1-F, respectively. GUS expression in longitudinally cut seeds of Chinese Spring (D) and KT3-5 (E) carrying the pActl-F, respectively. Blue arrowheads indicate GUS spots. em: embryo, en: endosperm, al: aleurone layer. Bar: $2 \mathrm{~mm}$.

bombardment using $2 \mu \mathrm{g}$ of Am (-877) IGN. For normalization of GUS activity, an internal control for transformation (Ubil-LUC) was added in a ratio of $1: 1$ to the reporter plasmid. After bombardment, 10 pieces of aleurone tissues were incubated as controls on filter paper impregnated with a solution containing $10 \mathrm{mM}$ $\mathrm{CaCl}_{2}, 50 \mathrm{U} \mathrm{ml}^{-1}$ nystatin and $150 \mathrm{mgl}^{-1}$ cefotaxime. The remaining 10 pieces of aleurone tissues were incubated on filter paper impregnated with the above solution further containing $10^{-6} \mathrm{M} \mathrm{GA}_{3}$. After incubation at $24^{\circ} \mathrm{C}$ for $48 \mathrm{~h}$, the cultured tissues were harvested. Preparation of extracts and GUS assays were conducted according to the procedure described by Lanahan et al. (1992). For the quantitative GUS assay, each bombarded aleurone tissue was homogenized in $200 \mu \mathrm{l}$ lysis buffer. One hundred microliters of each extract from the aleurone tissues were added to $400 \mu \mathrm{l}$ lysis buffer containing $1 \mathrm{mM} 4$-methyl-umbelliferyl $\beta$-D-glucuronide (MUG, Sigma) and incubated at $37^{\circ} \mathrm{C}$. At 0,2 and $4 \mathrm{~h}$ after the start of incubation, a $100 \mu \mathrm{l}$ aliquot was taken out from the reaction mixture and the reaction was terminated by the addition of $400 \mu \mathrm{l}$ of $0.2 \mathrm{M} \mathrm{Na}_{2} \mathrm{CO}_{3}$. The GUS activity was measured as intensity of the fluorescence excited at $365 \mathrm{~nm}$ and emitted at $455 \mathrm{~nm}$ using a spectrofluorophotometer (RF-5300PC, Shimadzu). The GUS activity was normalized against the LUC activity of the internal control that was measured using $50 \mu \mathrm{l}$ of each extract by a luciferase assay system (Promega). Normalized GUS activity was expressed by multiplying the ratio of GUS activity/LUC activity by 1000 (Figures 2 and 3C). Each experiment was replicated using at least 6 samples $(\mathrm{n}>6)$. 


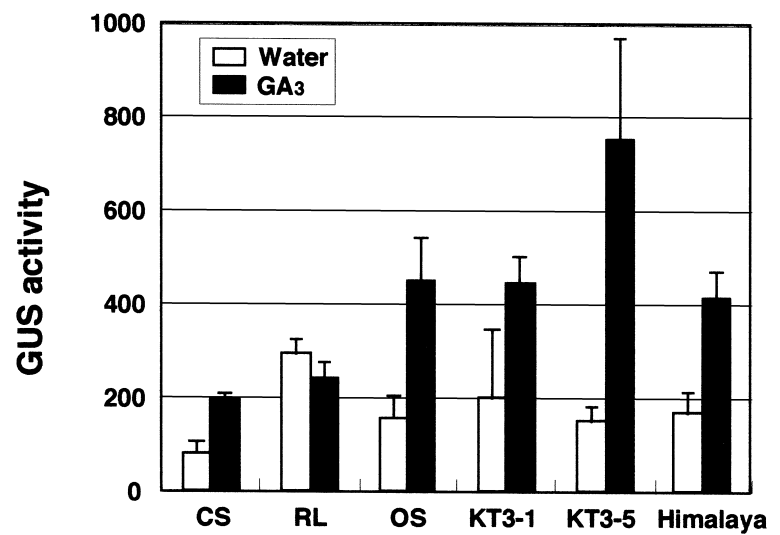

Figure 2. GUS expression in aleurone tissues of wheat and barley. An $\alpha$-amylase promoter-GUS reporter construct Am (-877) IGN was used to test the efficiency of transformation by particle bombardment in aleurone tissues of three hexaploid wheat varieties Chinese Spring (CS), RL4137 (RL) and OS21-5 (OS), two diploid varieties KT3-1 and KT3-5, and a barley variety Himalaya. Isolated aleurone tissues were bombarded and incubated at $24^{\circ} \mathrm{C}$ for $48 \mathrm{~h}$, and GUS activity in the tissue extracts was fluorophotometrically measured. The GUS activity was normalized against the activity of the LUC internal control $(1 \mu \mathrm{M}$ 4-MU $\mathrm{h}^{-1}$ per LUC1000). The means and standard errors are shown for bombardment experiments repeated at least six times.

Figure 2 shows the normalized GUS activity in the aleurone tissues of three hexaploid varieties Chinese Spring, RL4137 and OS21-5, two diploid wheat varieties KT3-1 and KT3-5, and a barley variety Himalaya, each bombarded with Am (-877) IGN. In Chinese Spring, the GUS activity was very low both in GA-treated and non-treated aleurone tissues although the activity was increased two- to three-fold by GA treatment. As mentioned above, the GUS activity was also low in Chinese Spring embryos and seeds bombarded with pActl-F (Figure 1A and D). The GUS activity in the aleurone tissues of RL4137 was three- to four-fold that of Chinese Spring in non-GA-treated cells and apparently not much affected by GA treatment (Figure 2). Such properties of RL4137 were repeatedly observed in some other experiments (data not shown). However, it remains unknown why the GUS activity in RL4137 aleurone tissues is relatively high without GA and less influenced by added GA. In OS21-5, KT3-1, KT3-5 and Himalaya, GUS activity was low in non-GA-treated cells and significantly increased by GA treatment. Among these varieties, KT3-5 aleurone tissues showed the most dramatic increase of GUS activity by addition of GA. The activity was about five-fold of that without GA. An eight- to ten-fold increase was observed in some other experiments (data not shown). The GUS activity in KT31, the parent line of KT3-5, was significantly lower than that of KT3-5 for an unknown reason. However, it might have been due to the difference in the maturity of seeds. The early-flowering variety KT3-5 set completely mature seeds in our field, whereas the field conditions here of high temperature and high humidity during the flowering season of the parent variety KT3-1 hinder the development of its seeds, resulting in poor seeds having immature embryos and almost lacking endosperms.

Efficient transient expression was seen in both the embryos and the aleurone layers of KT3-5 seeds (Figure $1 \mathrm{~B}$ and E). The activity of the $\alpha$-amylase promoter introduced into the aleurone tissues was dramatically enhanced by the addition of GA (Figure 2). The $\alpha$ amylase activity was unstable in the aleurone tissues of immature seeds with water contents of over $20 \%$, while it was stably high in those of fully mature seeds with water contents of $20 \%$ or lower (data not shown). Thus, aleurone tissues of mature dry seeds (60 DAP) of KT3-5 were used for the following transient assay for investigating the regulation of $\alpha$-amylase expression by GA.

In the aleurones, GA induces the transcription of genes encoding $\alpha$-amylase and other hydrolytic enzymes responsible for mobilizing endosperm reserves (Fincher, 1989). The induction of $\alpha$-amylase expression is controlled through interactions of regulatory proteins with cis-acting elements such as Gibberellic Acid Response Element (GARE) in the $\alpha$-amylase promoter (Rogers et al. 1994). Recently, a GA-inducible MYB transcription factor GAMYB, which specifically binds to a TAACAAA box in GARE in the $\alpha$-amylase promoter and activates the gene expression, has been isolated from barley (Gubler et al. 1995). To confirm the validity of KT3-5 in the amylase expression system, we cloned a cDNA derived from TmGAMyb of $T$. monococcum, which corresponds to GAMyb encoding the barley GAMYB, based on its homology to barley GAMyb. A cDNA library was constructed using embryos derived from immature seeds (10 DAP) of KT3-5 (Clonetech). Rapid amplification of the $5^{\prime}$ and $3^{\prime}$ ends of the cDNA was performed according to the manufacturer's instruction using $5^{\prime}$ or $3^{\prime}$ gene-specific primers, TmGAMybA6 (5'-GTTGGGCCTGAGGTGGTTCGCCC-3') or TmGAMyb-S2 (5'-GCGGCTCCTGCGATGCA-3'), based on the sequence of the barley GAMyb, and an adapter primer. PCR fragments were cloned into pBluescript $\mathrm{SK}^{+}$(Stratagene) by the TA-cloning method. The cloned cDNA fragment was sequenced by the DyeDeoxy terminator cycle sequencing method using an Applied Biosystems Genetic analyzer 310 DNA sequencer. Then, to test whether GA controls the expression of the TmGAMyb homolog corresponding to the obtained cDNA and $\alpha$-amylase, Northern hybridization analysis was carried out by using each cDNA as a probe. Total RNA was extracted from embryos isolated from seeds, which had been incubated in $10^{-6} \mathrm{M} \mathrm{GA}_{3}$ solution containing $10 \mathrm{mM} \mathrm{CaCl}_{2}$. Twenty $\mu \mathrm{g}$ of the total RNA was electrophoresed on a $1.2 \%$ formaldehyde agarose gel. The RNAs were blotted 
onto a nylon membrane (Hybond- ${ }^{+}$, Amersham Pharmacia biotech) and hybridized with a DIG-labeled cDNA derived from a $T m G A M y b$ homolog or $\alpha$-amylase. Northern hybridization was performed as described by Engler-Blum et al. (1993).

The result of the sequence analysis showed that the obtained cDNA (accession no. AB214883) contained an ORF of $1659 \mathrm{bp}$ encoding 552 amino acids and showing $96.6 \%$ and $86.2 \%$ identities to the barley and rice GAMYBs, respectively. As shown in Figure 3A, the expression of the gene corresponding to the cDNA was first detected at $12 \mathrm{~h}$ after the start of incubation with $\mathrm{GA}_{3}$, while the expression of $\alpha$-amylase started at $24 \mathrm{~h}$. These results show that the expression of the gene corresponding to the cDNA was induced by GA prior to the induction of the $\alpha$-amylase expression. The homology of the sequence and the expression pattern suggest that the obtained cDNA was derived from TmGAMyb. The Genomic Southern hybridization analysis indicated that the genome of $T$. monococcum contains only a single copy of this gene (data not shown).

The Act1-TmGAmyb effector construct used in the transient assays was synthesized by cloning the rice Actin1 promoter (MacElroy et al. 1990) and fragments containing the coding regions of TmGAMyb into a pUC19 vector. The rice Actinl promoter and the 5' untranslated leader sequence (including intron 1) in pDM302 (Cao et al. 1992) were excised as a HindIII fragment and cloned into the HindIII site of the pUC19based pTH-2. The PCR fragment containing the TmGAMyb coding region was cloned into the pBluescript $\mathrm{SK}^{+}$(Stratagene) T-vector. The entire insert was excised as a SalI-NotI fragment and cloned into the Sall-NotI site of the pTH-2-fused Actin1 promoter. Then, the SphI-SalI fragment was excised to remove the CaMV $35 \mathrm{~S}$ promoter from $\mathrm{pTH}-2$. For the expression analysis of $\alpha$-amylase regulated by TmGAMYB, $2 \mu \mathrm{g}$ of the reporter construct Am $(-877)$ IGN and 0.1 to $2 \mu \mathrm{g}$ of the effector construct were mixed to prepare bombardment mixtures with different ratios of the two constructs.

To confirm the validity of KT3-5 in the direct assay using aleurone tissues of seeds, we examined whether the transcript from the Act1-TmGAmyb effector construct could transactivate a reporter construct containing a GUS gene driven by Am (-877) IGN (Figure 3B). The aleurone tissues were bombarded with the reporter construct or its mixture with the effector construct and were incubated in water (control) or $\mathrm{GA}_{3}$ solution at $24^{\circ} \mathrm{C}$ for $48 \mathrm{~h}$. As shown in Figure $3 \mathrm{C}, \mathrm{GA}_{3}$ induced the GUS expression in the Am (-877) IGN-transformed tissues. In the absence of $\mathrm{GA}_{3}$, the TmGAMYB effector also induced the expression. The highest expression level was achieved in the tissues co-transformed with $1 / 4$ volume of the TmGAMYB effector, and the activity was
A

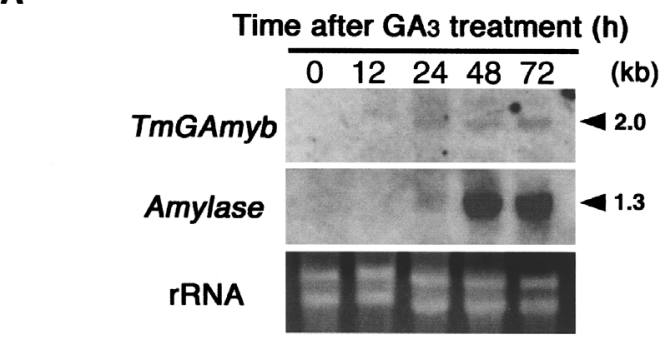

B

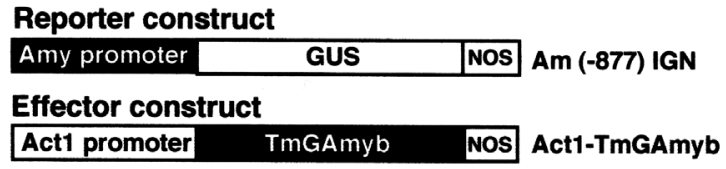

C

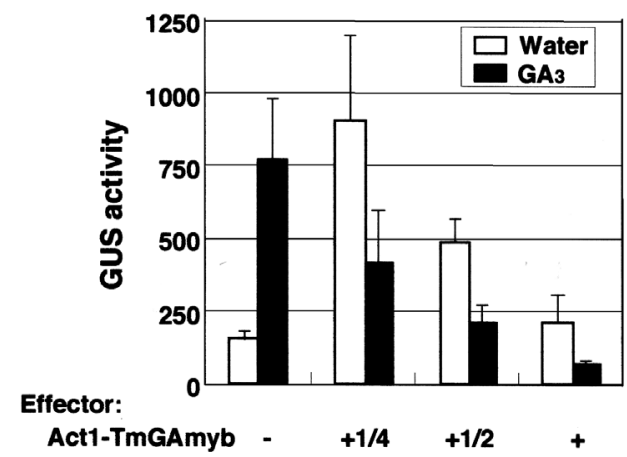

Figure 3. Regulation of the expression of $\alpha$-amylase and TmGAMyb. (A) Effect of $\mathrm{GA}_{3}$ on TmGAMyb and $\alpha$-amylase expression in wheat embryos. Twenty $\mu \mathrm{g}$ of total RNA per lane was separated on formaldehyde agarose gel, blotted onto a nylon membrane and hybridized with either DIG-labeled TmGAMyb or $\alpha$-amylase probe as indicated on the left. The time after the $\mathrm{GA}_{3}$ treatment is indicated at the top. The size of the mRNA detected from each blot is indicated on the right. (B) Structures of the effector and reporter constructs. Am $(-877)$ IGN is a reporter construct with a barley high-pI $\alpha$-amylase promoter driving the intron-GUS-Nos reporter cassette. Act1TmGAmyb is an effector construct with TmGAMyb cDNA inserted downstream of a rice Actin1 promoter. Nos, nopaline synthase. (C) Quantitative analysis of the GUS activity in the aleurone tissues of KT3-5 bombarded with the Am (-877) IGN and the Act1-TmGAmyb, and incubated at $24^{\circ} \mathrm{C}$ for $48 \mathrm{~h}$. The effector construct used in the cobombardment experiments in the presence of the reporter construct is indicated below the graph: + and - indicate the presence and absence of each construct, respectively. $-,+1 / 4,+1 / 2$ and + represent $0,1 / 4$, $1 / 2$ and 1 volume of DNA of the effector construct, respectively, relative to 1 volume of Am (-877) IGN. The closed and open columns show the GUS activity in the aleurone tissues incubated in the solution with $\mathrm{GA}_{3}$ and without it, respectively. The GUS activity was normalized against the activity of the LUC internal control $(1 \mu \mathrm{M} 4-$ $M U \mathrm{~h}^{-1}$ per LUC1000). The means and standard errors are shown for bombardment experiments repeated at least eight times.

eight-fold of that in the tissues transformed with Am $(-877)$ IGN alone without $\mathrm{GA}_{3}$-treatment. These results suggest that the obtained cDNA contains a gene encoding TmGAMYB, an orthologue of barley GAMYB that functions as an activator for $\alpha$-amylase. The tissues co-transformed with Am (-877) IGN and $1 / 2$ or 1 volume of Act1-TmGAmyb showed lower GUS activity. 
In addition, GUS activity was lower in $\mathrm{GA}_{3}$-treated tissues co-transformed with Am (-877) IGN and Act1TmGAmyb than in $\mathrm{H}_{2} \mathrm{O}$-treated tissues. The overexpression of TmGAMYB may have reduced the effect of the gene through either co-suppression between the introduced TmGAMYB and the preexisting TmGAMYB induced by $\mathrm{GA}_{3}$ treatments or squelching transcription of the TmGAMyb by sequestering some components such as co-activators necessary for the transcription.

Since mature seeds are physiologically more stable than immature seeds, and have fully differentiated mature embryos and starchy endosperms, the assay system using mature seeds is more suitable than that using immature seeds for investigating the roles of aleurone layers and their interactions with endosperms and embryos. Mature seeds are much easier to handle than immature seeds that often vary in their developmental stages. Moreover, mature seeds can be easily stored for a long time without any change in their quality, and can be used at any time of the year. This study showed highly efficient transient expression in the aleurone layers and embryos in the mature seeds of KT35 , and the promoter of $\alpha$-amylase was markedly activated by GA. The transient expression system using the aleurone tissues of KT3-5, a diploid wheat variety having simpler genomic construction than hexaploid common wheat, provides a convenient tool for investigating the molecular mechanisms of gene expression and regulation by plant hormones in seeds.

\section{Acknowledgements}

The authors would like to thank Dr. J. Jacobsen for kindly providing the Am (-877) IGN. This work was supported by a grant from the Ministry of Education, Culture, Sports, Science and Technology of Japan (grant no. 17780007).

\section{References}

Cao J, Duan X, McElroy D, Wu R (1992) Regeneration of herbicide resistant transgenic rice plants following microprojectile-mediated transformation of suspension culture cells. Plant Cell Rep 11: 586-591

Engler-Blum G, Meier M, Frank J, Muller GA (1993) Reduction of background problems in nonradioactive Northern and Southern blot analyses enables higher sensitivity than ${ }^{32} \mathrm{P}$-based hybridizations. Anal Biochem 210: 235-244

Fincher GB (1989) Molecular and cellular biology associated with endosperm mobilization in germinating cereal grains. Annu Rev Plant Physiol Plant Mol Biol 40: 305-346

Gilroy S, Jones RL (1994) Perception of gibberellin and abscisic acid at the external face of the plasma membrane of barley (Hordeum vulgare L.) aleurone protoplasts. Plant Physiol 104: 1185-1192

Gomez-Cadenas A, Zentella R, Walker-Simmons MK, Ho TH (2001) Gibberellin/ abscisic acid antagonism in barley aleurone cells: site of action of the protein kinase PKABA1 in relation to gibberellin signaling molecules. Plant Cell 13: 667-679

Gubler F, Kalla R, Roberts JK, Jacobsen JV (1995) Gibberellinregulated expression of a myb gene in barley aleurone cells: evidence for Myb transactivation of a high-pI alpha-amylase gene promoter. Plant Cell 7: 1879-1891

Jacobsen JV, Close TJ (1991) Control of transient expression of chimeric genes by gibberellic acid and abscisic acid in protoplasts prepared from mature barley aleurone layers. Plant Mol Biol 16: 713-724

Lanahan MB, Ho THD, Rogers SW, Rogers JC (1992) A gibberellin response complex in cereal [alpha]-amylase gene promoters. Plant Cell 4: 203-211

Lovegrove A, Hooley R (2000) Gibberellin and abscisic acid signalling in aleurone. Trends Plant Sci 5: 102-110

McElroy D, Zhang W, Cao J, Wu R (1990) Isolation of an efficient actin promoter for use in rice transformation. Plant Cell 2: 163-171

Robertson M, Cuming AC, Chandler PM (1995) Sequence analysis and hormonal regulation of a dehydrin promoter from barley, Hordeum vulgare. Physiologia plantrum 94: 470-478

Rogers JC, Lanahan MB, Rogers SW (1994) The cis-acting gibberellin response complex in high $\mathrm{pI}$ alpha-amylase gene promoters. Requirement of a coupling element for high-level transcription. Plant Physiol 105: 151-158

Shen Q, Gomez-Cadenas A, Zhang P, Walker-Simmons MK, Sheen J, Ho TH (2001) Dissection of abscisic acid signal transduction pathways in barley aleurone layers. Plant Mol Biol 47: 437-448

Vasil V, Marcotte WR Jr, Rosenkrans L, Cocciolone SM, Vasil IK, Quatrano RS, McCarty DR (1995) Overlap of Viviparous1 (VP1) and abscisic acid response elements in the Em promoter: G-box elements are sufficient but not necessary for VP1 transactivation. Plant Cell 7: 1511-1518

Zentella R, Yamauchi D, Ho TH (2002) Molecular dissection of the gibberellin/abscisic acid signaling pathways by transiently expressed RNA interference in barley aleurone cells. Plant Cell 14: 2289-2301 